\title{
Werken in de klusseneconomie: een literatuurstudie
}

\author{
Fabian Dekker ${ }^{*}$
}

In verschillende landen wordt gediscussieerd over de opkomst en gevolgen van de klusseneconomie. Ook in Nederland. De eerste bijdrage van het dossier over de klusseneconomie geeft op basis van de literatuur een overzicht van de gevolgen van online platforms voor de arbeidsmarkt, arbeidsorganisatie en arbeidsverhoudingen. Uitkomsten suggereren onder andere dat de klusseneconomie als verschijnsel past in een breder transformatieproces naar een meer flexibele arbeidsmarkt, waarbij zich vergelijkbare beleidsuitdagingen voordoen zoals bij de opkomst van zelfstandigen zonder personeel (zzp'ers).

\section{Inleiding}

Onze samenleving wordt in toenemende mate bepaald door nieuwe technologie. Digitalisering, robotisering, kunstmatige intelligentie, nanotechnologie en 3Dprinters veranderen de omgang tussen mensen, bedrijven en landen (Rathenau Instituut, 2015). Door groei van de rekenkracht van computers verandert ook de arbeidsmarkt. ICT maakt het bijvoorbeeld mogelijk om productieprocessen op te knippen en te verplaatsen over landsgrenzen (Weil, 2014), en processen van digitalisering zetten routinematige werkzaamheden en administratieve beroepen in het middensegment van de arbeidsmarkt onder druk (zie bijvoorbeeld Autor, 2013; Borland \& Coelli, 2017). Ook in ons land werken inmiddels steeds minder mensen in routinematige beroepen (Centraal Bureau voor de Statistiek; CBS, 2017; Uitvoeringsinstituut Werknemersverzekeringen; UWV, 2015). Daarnaast biedt technologische verandering de mogelijkheid om allocatieprocessen op de arbeidsmarkt anders vorm te geven. Via het gebruik van online platforms kunnen vragers en aanbieders van producten en diensten elkaar zonder tussenkomst van intermediaire partijen ontmoeten en direct transacties afsluiten. In het consumentendomein is Marktplaats waarschijnlijk het bekendste voorbeeld van deze nieuwe manier waarop mensen elkaar vinden. Wanneer mensen tweedehands goederen aan elkaar verhuren, wordt er gesproken over de deeleconomie (Frenken e.a., 2015). Airbnb is hier een exemplarisch voorbeeld van. In het arbeidsdomein hebben we inmiddels ook veel initiatieven zien ontstaan, zoals Uber (taxibranche), Helpling (schoonmaakbranche), Deliveroo (maaltijdbezorging) en werkmarktplaatsen zoals Werkspot of Croqqer. Er wordt in die gevallen gesproken over de 'op afroep' 'gig'6 of 'klusseneconomie'. Een van de meest voorkomende (en beknopte) omschrijvingen van de klusseneconomie is het via online platforms

* Fabian Dekker is als arbeidssocioloog verbonden aan Regioplan Beleidsonderzoek en lid van de redactie van Beleid en Maatschappij. 
aanbieden en vinden van kleinschalige vormen van betaalde dienstverlening (Balaram, Warden \& Wallace-Stephens, 2017). Soms regelen de online platforms hierbij ook de betalingen. Bij andere platforms is dit een zaak van de opdrachtgever en opdrachtnemer.

Wat het bedrijfsmodel van een online platform betreft bestaan er eveneens de nodige varianten. In het algemeen rekenen platforms een bepaald percentage over de overeengekomen opdracht tussen opdrachtgever en opdrachtnemer of ze vragen om een vast bedrag per plaatsing van een klus (Eurofound, 2015). Binnen de klusseneconomie zelf is een nadere typologie aan te brengen naar online platforms die zich richten op virtuele micro-jobs (zoals Amazon's Mechanical Turk), platforms rond (vaak gecertificeerde) zelfstandige professionals (zoals PeoplePerHour) en platforms die zich richten op fysieke vormen van lokale dienstverlening (zoals TaskRabbit). Weer een andere indeling betreft het onderscheid naar 'crowdwork' (zoals Amazon's Mechanical Turk) en 'werk op afroep' (zoals Uber) (zie De Stefano, 2016). En achter deze uiteenlopende online platforms en typeringen gaat weer een minstens zo'n heterogene groep werkenden schuil (zie Valenduc \& Vendramin, 2017).

Naast technologische ontwikkeling en nieuwe drijfveren van werkenden wordt de opkomst van de klusseneconomie onder andere gedreven door politiek-institutionele processen. Vooral sinds de jaren tachtig en negentig van de vorige eeuw is in Amerika en Europa het politieke besef ontstaan dat ondernemingen de ruimte moeten hebben om flexibel om te springen met hun personeel. Uitingen van privatisering, deregulering en flexibilisering van werk zijn ook in Nederland zichtbaar en hebben mede ten grondslag gelegen aan nieuwe zoektochten van werkgevers naar een meer flexibele inzet van werkenden (vergelijk Friedman, 2014; Van Doorn, 2017). Vaststaat ook dat de opkomst van de klusseneconomie een aantal duidelijke voordelen heeft. Twee hiervan hebben te maken met een daling van de transactiekosten en een efficiënte koppeling tussen vrager en aanbieder. Maar het maakt de arbeidsmarkt niet alleen goedkoper en allocatieprocessen sneller. Via het achterlaten van gebruikersbeoordelingen neemt bovendien de transparantie toe. En tegelijkertijd roept het tal van vragen op. Zo is er bijvoorbeeld onduidelijkheid over de juridische status van de platformwerker of gig economy worker. Is er sprake van een arbeidsovereenkomst of zijn platformwerkers freelancers die zelf bepalen wanneer en bij wie ze klussen aannemen? Ook roept het vragen op over de arbeidsomstandigheden van platformwerkers en over het ontstaan van sociale ongelijkheid, zoals de discussie rond Amazon's online platform Mechanical Turk en taxidienst Uber eerder al eens lieten zien (Scholz, 2016). Volgens sommige auteurs delen platformwerkers vooral kenmerken met werknemers in het precaire deel van de arbeidsmarkt en creëert platformisering een zogenaamde share the scraps economy (Reich, 2015). Anderen associëren platformisering daarentegen met een nieuwe kans voor economische inclusie van kwetsbare groepen op de arbeidsmarkt (Graham, Hjorth \& Lehdonvirta, 2017).

In het kader van het Dossier over werken in de klusseneconomie zal ik in deze bijdrage een beknopt overzicht geven van een aantal empirische studies die ingaan op de gevolgen van platformisering voor betaalde arbeid. Want ondanks dat platformisering een actueel en frequent bediscussieerd beleidsonderwerp is, 
zie bijvoorbeeld de rondetafelbijeenkomsten over werk in de platformeconomie in de Tweede Kamer eind 2017, ontbreekt het vooralsnog aan literatuurstudies die gebruikt kunnen worden om het beleidsdebat scherper te voeren. Ik ben daarom op zoek gegaan naar wetenschappelijke publicaties waarin de relatie tussen platformisering en werk ter sprake komt. Hiervoor is gebruikgemaakt van zowel Nederlands- als Engelstalige zoektermen in verschillende sociaalwetenschappelijke databestanden, zoals EconLit (bevat economische publicaties vanaf 1969) en Sociological Abstracts (bevat sociaalwetenschappelijke publicaties vanaf 1952). Om te zoeken naar bruikbare publicaties zijn trefwoorden gebruikt zoals: 'gig economy', 'online work', 'on demand work', 'platform economy' en 'platform labo(u)r' in combinatie met de zoektermen 'labour', 'work' of 'employment' (inclusief de Nederlandstalige equivalenten). Publicaties die ingaan op andere uitingsvormen van platformisering, zoals de deeleconomie, blijven buiten beschouwing. Ten slotte is er bewust geen restrictie opgelegd ten aanzien van de tijdsperiode waarbinnen gezocht wordt, om zo het aantal potentieel geschikte studies te vergroten. Om de gevolgen van platformisering voor betaalde arbeid analytisch in te kaderen maak ik gebruik van een drietal onderling verbonden arena's die met elkaar het arbeidsbestel vormen (Van Hoof \& Van Ruysseveldt, 2006): de arbeidsmarkt ('wie werken er in een klusseneconomie?'), de arbeidsorganisatie ('betekent platformisering het einde van de arbeidsorganisatie?') en de arbeidsverhouding ('welke nieuwe arbeidsrelaties ontstaan er onder invloed van platformisering?').

\section{Platformisering en de arbeidsmarkt}

In het maatschappelijke debat lezen we vaak dat de platformwerker aan een gestage opkomst bezig is. En niet alleen in Nederland. De Groen e.a. (2017) stellen dat in totaal 5,9 procent van de Europese werkzame beroepsbevolking in meer of mindere mate inkomens verwerft via een online platform in 2016. Dit betreft 12,8 miljoen personen (15-64 jaar) die actief zijn via 173 platforms. Cross-nationaal onderzoek maakt verder duidelijk dat meer dan een miljoen werkenden in Europa voor hun inkomen volledig afhankelijk zijn van inkomen uit online platforms (Drahokoupil \& Piasna, 2017). De klusseneconomie is echter een bijzonder heterogeen segment van werkenden die vooral 'bijklussen', van laaggeschoold schoonmaakwerk tot en met hoger geschoolde consultancy- en ICT-taken. Ook verkennend kwalitatief onderzoek van Schor e.a. (2017) geeft grond voor de stelling dat werkenden vooral aanvullend bijklussen via digitale platforms. In de taxibranche lijken werkenden daarentegen wel bovengemiddeld vaak afhankelijk te zijn van inkomsten uit online platforms (zoals Uber). Wat achtergrondkenmerken betreft zijn platformwerkers in het algemeen iets vaker man, relatief jong en eerder actief in stedelijke gebieden, maar er is ook in dit geval sprake van de nodige variëteit (Huws \& Joyce, 2016; Lepanjuuri, Wishart \& Cornick, 2018). Ze houden zich vooral bezig met het aanbieden van persoonlijke diensten in de creatieve en zakelijke dienstverlening. Met name de koeriersdiensten springen hierbij in het oog. Opvallend is ook dat het werken via een online platform voor werkenden een 'tussenstation' lijkt te zijn. In het Verenigd Koninkrijk bijvoorbeeld, geeft 'slechts' 
41 procent aan in de komende twaalf maanden zijn werkzaamheden in de klusseneconomie voort te zetten (Lepanjuuri e.a., 2018). In Amerikaans onderzoek lijkt de opmars van de 'gig economy worker' wat tegen te vallen. Volgens onderzoek van de economen Katz en Krueger (2016) werkt slechts 0,5 procent van de werkende beroepsbevolking via tussenkomst van een online platform in 2015. Van een aanhoudende online dynamiek op de arbeidsmarkt lijkt dus zeker niet altijd sprake te zijn. De toekomstige omvang van de klusseneconomie zal per land dan ook in sterke mate afhangen van de lokale wet- en regelgeving (zie ook Murad \& Hook, 2015). Vooral de onderkant van de arbeidsmarkt lijkt problemen te ondervinden van platformisering van werk. De zogenaamde groep 'microwerkers' die veelal kortlopende en kleinschalige taken verricht via bemiddeling van online platforms is met name te traceren in Amerika, Pakistan, de Filipijnen en binnen Europa in Engeland. Voorbeelden van dergelijke kortdurende taken zijn datainvoer, kleine vertaalklusjes, schoonmaakwerk en hondenuitlaatdiensten. Uit Brits onderzoek komt naar voren dat ongeveer een kwart van alle klussenwerkers inkomsten heeft onder de $£ 7,50$ per uur (Lepanjuuri e.a., 2018) en 74 procent van alle Amerikaanse Uber- en Lyft-chauffeurs verdient minder dan het minimumloon van de betreffende staat (Zoepf e.a., 2018). Ook in ons land is veel discussie over Uber, waarbij Uber een commissie hanteert tot 25 procent van de ritprijs. Gegeven de lage uurtarieven en scherpe onderlinge concurrentieverhoudingen worden microwerkers nog wel eens beschouwd als het nieuwe precariaat van de arbeidsmarkt (Webster, 2016). Hoe ziet de situatie er in Nederland uit?

In een toekomstverkenning van het Sociaal en Cultureel Planbureau (SCP, 2016) wordt de verwachting uitgesproken dat werk steeds meer het karakter van taken en projecten zal krijgen in plaats van vastomlijnde beroepen. Voortschrijdende technologische en sociaal-culturele ontwikkelingen zijn de vaak terugkerende voorspellers. Verkennend onderzoek naar de omvang van de platformeconomie in Oostenrijk, Zweden, het Verenigd Koninkrijk en Nederland laat zien dat ongeveer tussen 11 procent en 23 procent van alle volwassenen inkomen verwerft via een online platform. Deze studie bevat echter ook de verkoop van goederen op platforms zoals eBay en Amazon en overschat daarom de daadwerkelijke omvang van de klusseneconomie (zie voor een uiteenzetting De Groen e.a., 2017). Volgens onderzoekers van Toegepast Natuurwetenschappelijk Onderzoek (TNO, 2016) heeft ongeveer één op de acht volwassenen in de leeftijdsgroep 16-70 jaar op enig moment geld uit werk verdiend via een online platform. Dit zou gaan om ongeveer 1,4 miljoen mensen. Net zoals voor de Europese werkenden geldt, geeft een minderheid van de Nederlandse platformwerkers (6 procent) aan dat inkomsten via een online platform de enige of belangrijkste bron van inkomen is. En uit de verdeling van het persoonlijk inkomen van de platformwerkers blijkt dat we ook in ons land met een bijzonder heterogeen segment te maken hebben: de persoonlijke inkomens variëren van maximaal $€ 18.000$ (32 procent) per jaar tot meer dan $€ 60.000$ (6 procent) per jaar. Platformgebruikers lijken vooralsnog jonger en hoger opgeleid te zijn (Doll, Van Hoenselaar \& Van der Cruijsen, 2017). Als het gaat om werkzaamheden die platformwerkers in Nederland uitvoeren, gaat het met name om professionele vormen van dienstverlening in de zakelijke sectoren van de economie. Hoewel een grote spreiding schuilgaat achter de groep klussen- 
werkers, zijn er vooralsnog geen eenduidige aanwijzingen dat de opkomst van de klusseneconomie gemiddeld genomen leidt tot nieuwe vormen van ongelijkheid op de Nederlandse arbeidsmarkt. De grootste groep werkenden lijkt namelijk vooral bij te klussen naast andere inkomensbronnen. Dit neemt niet weg dat zowel in het buitenland als in ons land voorbeelden te vinden zijn van marktplaatsen die arbeidsrisico's lijken af te schuiven op werkenden, zoals de discussies over Deliveroo en Uber laten zien. Bij Deliveroo werden werknemers bijvoorbeeld gedwongen om toekomstige taken als zzp'er uit te voeren, wat vragen opriep over de juridische status van het dienstverband.

\section{Platformisering en de arbeidsorganisatie}

Een vaak gehoorde stelling is dat de inzet van online platforms de arbeidsorganisatie overbodig maakt. Vanuit de transactiekostentheorie (Williamson, 1985) verdwijnt er immers een tussenschakel in de keten die de ruil van diensten tussen personen mogelijk maakt. Het is overigens maar de vraag of aan de organisatie als entiteit in de toekomst een einde komt. Door technologische ontwikkeling zijn platformorganisaties weliswaar minder afhankelijk van allerlei intermediaire partijen, maar het blijven in zichzelf traditionele organisaties die marges rekenen voor hun diensten (zoals het plaatsen van klussen) en ze worden bestuurd door (klassieke) chief executive officers (CEO's). Toch zorgt platformisering ervoor dat delen van productieprocessen gemakkelijk opgeknipt kunnen worden in kleinere taken, en bestaande bedrijfsmodellen komen er wel degelijk door onder druk te staan. Todoli-Signes (2017) heeft in zijn werk een aantal veranderingen voor bestaande bedrijfsmodellen op een rij gezet. Allereerst zijn online platformorganisaties volgens hem minder afhankelijk van personeel. Daarnaast maakt technologie opschaling mogelijk, het is immers relatief gemakkelijk om (op internationale schaal) werkenden te mobiliseren, de zoekkosten voor bedrijven nemen af en, ten slotte, worden verschillende platforms beschouwd als zogenaamde technology companies, waardoor het moeilijk is om aansprakelijkheid te claimen in het geval van eventuele schade. Tegelijkertijd kan men zich afvragen of de transactiekosten niet ook weer deels toenemen. Denk hierbij bijvoorbeeld aan de soms nog altijd lange zoekduur en dus hoge zoekkosten voor platformwerkers voordat ze hun juiste opdrachten hebben gevonden (Berg, 2016). Ook ontbreekt het bij online platforms vaak aan partijen die belangenoverstijgend kunnen optreden in het geval van een conflict tussen platformmedewerker en opdrachtgever. Dit lijkt ook een van de uitdagingen te zijn bij meer grootschalige toepassingen van de blockchain-technologie: welke partij gaat eventueel misbruik tegen en wat te doen in het geval iemand zijn wachtwoorden en toegangscodes kwijt is? De beperkingen hebben er ook mee te maken dat in de praktijk bijna nooit sprake is van een volledige contractrelatie waarbij alle contractovereenkomsten vooraf en tot in detail zijn gespecificeerd (zie ook McAfee \& Brynjolfsson, 2017). In die gevallen zullen alsnog kosten worden gemaakt om activiteiten te coördineren en zal hoogstwaarschijnlijk worden gekozen voor het in stand houden van een organisatie in plaats van de markt volledig zijn werk te laten doen. Wat dat betreft is het nog maar 
zeer de vraag of klassieke organisaties daadwerkelijk op het punt van verdwijnen staan, zoals aanhangers van een disruptief perspectief op technologie vaak lijken te suggereren (vergelijk McKinsey, 2016).

\section{Platformisering en arbeidsverhoudingen}

Wat betekent platformisering voor de arbeidsverhoudingen? Een consequentie ervan lijkt te liggen in de teloorgang van het standaard arbeidscontract. Steeds vaker worden werkenden in Nederland op een flexibele manier tewerkgesteld, bijvoorbeeld als zzp'er (Euwals, De Graaf-Zijl \&Van Vuuren, 2016). Hoewel platforms zoals Uber in de taxibranche de al traditioneel veelvoorkomende flexibele arbeidsverhoudingen tussen opdrachtgever en opdrachtnemer lijken te intensiveren, ontstaat er in andere sectoren ook een grotere druk op de inzet van flexibele arbeidsverbanden en internationale outsourcing. In het laatste geval is bijvoorbeeld te denken aan laaggeschoold informatietechnologie-werk dat via digitale platforms gemakkelijker kan worden uitbesteed naar lagelonenlanden (Drahokoupil \& Piasna, 2017). Het is hierbij een terugkerende vraag of de meer flexibele arbeidsverbintenissen van platformwerkers gepaard gaan met voldoende autonomie en zeggenschap in het werk. Berg (2016) laat bijvoorbeeld zien dat platformwerk wordt gekenmerkt door een voortdurende roep om permanente beschikbaarheid in de richting van opdrachtgevers, waardoor werk- en privéleven sterk door elkaar zijn gaan lopen (zie ook Kuhn \& Maleki, 2015). Hoewel onderzoek naar de arbeidspositie van platformwerkers nog steeds schaars is, hebben we eerder vastgesteld dat de meeste platformwerkers vooral lijken bij te klussen naast andere inkomensbronnen. Ook in Nederland. In 2014 heeft inmiddels 7,5 procent van de Nederlandse werknemers meer dan één baan, een verschijnsel dat in Angelsaksische landen ook wel wordt bestempeld als moonlighting; het hebben van een extra bijbaan in de avonduren (Dorenbosch, Sanders \& Beudeker, 2015, 171). Een recente verkenning van de Sociaal-Economische Raad (SER, 2018) stelt dat inmiddels al ongeveer 600.000 mensen meer dan één baan hebben. Vooral de flexibiliteit om werktijden te kunnen bepalen, de mogelijkheid om jezelf te kunnen blijven ontwikkelen, de autonomie in het werk en het verwerven van een aanvullend inkomen zijn vaak gerapporteerde voordelen van baancombineerders (en klussenwerkers). Het gebrek aan sociale zekerheid en de onvoorspelbaarheid van toekomstige inkomens zijn voor klussenwerkers voor de hand liggende nadelen (zie voor een overzicht Broughton e.a., 2018). In het bijzonder wanneer zelfstandige platformwerkers met zaken als ziekte en arbeidsongeschiktheid te maken krijgen worden ze geconfronteerd met harde financiële consequenties. Ook in dit geval bieden andere inkomensvoorzieningen, bijvoorbeeld in loondienst, voor een deel uitkomst. Volgens onderzoek onder taxichauffeurs bij Uber is bijvoorbeeld 49 procent verzekerd voor gezondheidskosten via een werkgever, partner of familielid (Hall \& Krueger, 2015). Dit neemt niet weg dat onderverzekering bij kluswerkers die volledig afhankelijk zijn van inkomsten via online platforms, een reëel probleem is. 


\section{Conclusie: dubbelkarakter van de klusseneconomie}

Alles overziend kunnen we concluderen dat online platforms en de bijbehorende klusseneconomie in opkomst zijn. Maar tegelijkertijd is van een exponentiële ontwikkeling verre van sprake. Dit geldt voor Nederland, maar ook voor Europa en de Verenigde Staten. De klusseneconomie wordt vooral omgeven door een hoge mate van onzekerheid. Onzekerheid over zowel de toekomstige omvang van de klusseneconomie als de juridische status van 'gig workers' (OECD, 2016). Wat inschatting van de omvang betreft, is een complicerende factor de vaak inconsistente afbakening van het begrip klusseneconomie. Dit was voor Amerikaanse onderzoekers voldoende reden om begin dit jaar een Gig Economy Data Hub te lanceren om zo meer accurate gegevens te verzamelen over de opkomst en gevolgen van de klusseneconomie (zie Aspen Institute, 2017). Gebaseerd op het bestaande onderzoeksmateriaal valt wel de conclusie te trekken dat inherent optimistische dan wel pessimistische visies op werk vooralsnog onvoldoende houdbaar zijn. We hebben namelijk te maken met een bijzonder heterogeen segment werkenden en alles wijst erop dat kenmerken van de klusseneconomie zich goed laten rijmen met de al eerder ingezette ontwikkeling van flexibilisering van de arbeidsmarkt (De Stefano, 2016). En zoals de literatuur rond flexibilisering laat zien, heeft deze ontwikkeling zowel voor- als nadelen.

De logische verwachting is dat de klusseneconomie vooral voordelen biedt aan de bovenkant van de arbeidsmarkt. Hier ontstaat naar alle waarschijnlijkheid een win-winsituatie voor zowel opdrachtgever als opdrachtnemer. Opdrachtgevers komen gemakkelijk aan specialistische kennis voor een tijdelijke opdracht en voor ondernemende professionals is het werken via een online platform een manier om met een hoge mate van autonomie inkomsten te verwerven. Dit zijn vaak inkomsten naast andere inkomensbronnen, zoals loon, pensioen of een uitkering. Mijn verwachting hierbij is dat platformorganisaties voor hoger opgeleide, ondernemende werkenden vooral een basis zullen vormen voor een verdere hybridisering van werk (zie ook Kremer, Went \& Knottnerus, 2017). Werken in de klusseneconomie kan namelijk goed voorzien in een toegenomen behoefte aan autonomie (vergelijk IBO, 2015). In die zin zullen in de toekomst steeds meer mensen de voordelen kunnen inzien van het werken op basis van gigs. Tegelijkertijd zoeken werkenden naast autonomie minstens zo vaak naar inkomenszekerheid (Van der Klein e.a., 2016). De behoeften aan zowel autonomie als zekerheid komen bij uitstek tot uitdrukking in hybride arbeidsrelaties. Het is dan ook niet verwonderlijk dat het aandeel hybride arbeidsrelaties in ons land geleidelijk aan is toegenomen van 169.000 naar 251.000 personen in de periode 2005-2016 (CBS StatLine, 2018).

Door verschillende onderzoekers is ook geconstateerd dat werkenden aan de onderkant van de klusseneconomie vaak een laag inkomen hebben, en er zijn voorbeelden waarbij een werkrelatie wordt voorgesteld als zelfstandige arbeid, zoals de Deliveroo-casus laat zien. Zeker wanneer werknemers een minder sterke onderhandelingspositie hebben ten opzichte van werkgevers, wordt de opkomst van de klusseneconomie primair gedreven door werkgevers. In Amerika fluctueren gig jobs bijvoorbeeld sterk met de conjunctuur; de klusseneconomie neemt in 
omvang toe tijdens economische laagconjunctuur en daalt bij economische opleving (Friedman, 2014). Ook in landen als Griekenland en Spanje is de klusseneconomie opgekomen tijdens perioden van economische neergang (Eurofound, 2015). Voor werkenden die tegen wil en dank gebruikmaken van online platforms is de klusseneconomie een riskante zaak. Voor opdrachtgevers ligt dit anders. Tegen de achtergrond van een toegenomen nadruk op aandeelhouderswaarde binnen bedrijven is flexibilisering van de arbeidsinzet via online platforms een lonkend perspectief (vergelijk Dekker, 2016).

Vanuit beleidsperspectief roept platformisering een aantal vragen op die zeer herkenbaar zijn vanuit eerdere discussies over de flexibilisering van werk (zie bijvoorbeeld IBO, 2015). Zo is er juridische onduidelijkheid over de positie van de kluswerker in het arbeidsrecht. Wanneer zijn kluswerkers werknemer en wanneer zelfstandige? En hoe gaan we dit handhaven? In het regeerakkoord is hiertoe een aanzet gegeven door onder andere op basis van het uurtarief en de duur van de overeenkomst te bepalen of er sprake is van een status als zelfstandige. Ook zijn er verschillen in sociale bescherming tussen zelfstandige kluswerkers en werknemers. Zijn deze verschillen wenselijk of moet er in de toekomst sprake zijn van nieuwe vormen van solidariteit, ongeacht de contractvorm? Ten slotte kan de vraag worden gesteld onder welke condities platformisering bij kan dragen aan productiviteit, samenwerking en innovatie. Eerder onderzoek liet zien dat de opkomst van zelfstandige arbeid de innovativiteit van sectoren en bedrijven niet substantieel heeft verhoogd. Betekent de opkomst van de klusseneconomie dat we hiermee langzaam maar zeker ons economisch verdienmodel uithollen? Belangrijke vragen die nadere analyses vergen.

\section{Noot}

1 Journalist Tina Brown was de eerste die gebruik maakte van de term gig economy om flexibele arbeidsrelaties in een digitale economie te beschrijven.

\section{Literatuur}

Aspen Institute (2017). Future of work initiative partners with Cornell ILR School to launch the Gig Economy Data Hub. aspeninstitute.org, gerradpleegd op 13 februar 2018.

Autor, D. (2013). The task approach to labor markets: An overview. Journal of Labour Market Research, 1-15.

Balaram, B., Warden, J., \& Wallace-Stephens, F. (2017). Good Gigs. RSA.

Berg, J. (2016). Income security in the on-demand economy: Findings and policy lessons from a survey of crowdworkers (ILO Working Paper 74).

Borland, J., \& Coelli, M. (2017). Are robots taking our jobs? The Australian Economic Review, 50 (4): 377-397.

Broughton, A., Gloster, R., Marvell, R., Green, M., Langley, J., \& Martin, A. (2018). The experiences of individuals in the gig economy. www.gov.uk/government/uploads/system/ uploads/attachment_data/file/679987/171107_The_experiences_of_those_in_the_ gig_economy.pdf, geraadpleegd op 9 februari 2018. 
CBS (2017). Internationaliseringsmonitor 2017-IV. Den Haag: CBS.

CBS StatLine (2018). www.cbs.nl/nl-nl/maatwerk/2017/39/werkzame-beroepsbevolkingen-combibaan-2005-2016, geraadpleegd op 4 februari 2018.

Dekker, F. (2016). Outsourcing binnen Nederland: feiten en verklaringen. ESB, 101 (4742): 658-661.

De Stefano, V. (2016). The rise of the just-in-time workforce: on-demand work, crowdwork and labour protection in the gig economy. Genève: ILO.

Doll, M., Hoenselaar, F. van, \& Cruijsen, C. van der (2017). Het gebruik van platformbedrijven belicht. ESB, 4754 (102): 484-485.

Doorn, N. van (2017). Platform labor: on the gendered and racialized exploitation of lowincome service work in the 'on demand economy'. Information, Communication \& Society, 20 (6): 898-914.

Dorenbosch, L., Sanders, J., \& Beudeker, D. (2015). Multi-jobbing: wenselijke of onwenselijke arbeidsmarktdynamiek? In: CBS/TNO, Dynamiek op de Nederlandse arbeidsmarkt. Den Haag: CBS/TNO.

Drahokoupil, J., \& Piasna, A. (2017). Work in the platform economy: Beyond lower transaction costs. Intereconomics, 6: 335-340.

Eurofound (2015). New forms of employment. Dublin: Eurofound.

Euwals, R., Graaf-Zijl, M. de, \& Vuuren, D. van (2016). Flexibiliteit op de arbeidsmarkt. Den Haag: $\mathrm{CPB}$.

Frenken, K., Meelen, T., Arets, M., \& Glind, P. van de (2015). Wat is nu eigenlijk deeleconomie? Me Judice, 27 maart 2015. www.mejudice.nl.

Friedman, G. (2014). Workers without employers: shadow corporations and the rise of the gig economy. Review of Keynesian Economics, 2 (2): 171-188.

Graham, M., Hjorth, I., \& Lehdonvirta, V. (2017). Digital labour and development: impacts of global digital labour platforms and the gig economy on worker livelihoods. Transfer, 23 (2): 135-162.

Groen, W. de, Kilhoffer, Z., Lenaerts, K., \& Salez, N. (2017). The impact of the platform economy on job creation. Intereconomics, 6: 345-351.

Hall, J., \& Krueger, A. (2015). An analysis of the labor market for Uber's driver-partners in the United States (Working Paper). Princeton University.

Hoof, J. van, \& Ruysseveldt, J. van (2006). Arbeid in het moderne arbeidsbestel. In: J. van Ruysseveldt \& J. van Hoof (red.), Arbeid in verandering. Deventer: Kluwer.

Huws, U., \& Joyce, S. (2016). Crowd working survey: the size of the gig economy in Austria, Germany, the Netherlands, Sweden and UK. Hatfield: University of Hertfordshire.

IBO (2015). IBO Zelfstandigen zonder personeel. Den Haag: IBO.

Katz, L., \& Kruger, A. (2016). The rise and nature of alternative work arrangements in the United States, 1995-2010 (Working Paper 603). Cambridge: NBER.

Klein, M. van der, Aussems, C., Jansma, A., Gruijter, M. de, \& Piets, K. (2016). Een nieuwe generatie een nieuw geluid? Utrecht: Verwey-Jonker Instituut.

Kremer, M., Went, R., \& Knottnerus, A. (2017). Voor de zekerheid. Den Haag: WRR.

Kuhn, K.. \& Maleki, A. (2015). A workforce of micro-entrepreneurs: Online labor platforms and the sharing economy (Paper presented at the annual meeting of the Academy of Management). Vancouver.

Lepanjuuri, K., Wishart, R., \& Cornick, P. (2018). The characteristics of those in the gig economy (Research Paper 2018/2) BEIS.

McAfee, A., \& Brynjolfsson, E. (2017). Machine, platform, crowd. Londen: Norton.

McKinsey (2016). Independent work: choice, necessity, and the gig economy. McKinsey Global Institute. 
Murad, A., \& Hook, L. (2015, 22 oktober). Uber's international expansion chief steers for the exit after regulatory blows. Financial Times, 14.

OECD (2016). It's a gig, but is it a job? Parijs: OECD Observer.

Rathenau Instituut (2015). Werken aan de robotsamenleving. Den Haag: Rathenau Instituut.

Reich, R. (2015). The share-the-scraps economy Geraadpleegd op 3 februari 2018. Gedownload via www.robertreich.org.

Scholz, T. (2016). Uberworked and underpaid. How workers are disrupting the digital economy. Cambridge: Polity Press.

Schor, J., Attwood-Charles, J., Cansoy, M., Ladegaard, I., \& Wengronowitz, R. (2015). Dependence and precarity in the Platform Economy. Ongepubliceerd manuscript.

SCP (2016). De toekomst tegemoet. Den Haag: SCP.

SER (2018). De vele kanten van banen combineren. Den Haag: SER.

TNO (2016). Nieuwe schatting van de omvang van de Nederlandse 'Gig Economie'. www.tno.nl, gedownload op 18 januari 2018.

Todoli-Signes, A. (2017). The gig economy: employee, self-employed or the need for a special employment regulation? Transfer, 23 (2): 193-205.

UWV (2015). Administratieve beroepen. Amsterdam: UWV.

Valenduc, G., \& Vendramin, P. (2017). Digitalisation, between disruption and evolution. Transfer, 23 (2): 121-134.

Webster, J. (2016). Microworkers of the Gig Economy: separate and precarious. New Labor Forum, 25 (3): 56-64.

Weil, D. (2014). The Fissured Workplace. Cambridge: Harvard University Press.

Willamson, O. (1985). The economic institutions of capitalism. Firms, markets, relational contracting. New York: Free Press.

Zoepf, S., Chen, S., Adu, P., \& Pozo, G. (2018). The economics of ride-hailing: Driver revenue, expenses and taxes. Cambridge: MIT CEEPR. 